\title{
Half-Blind to the Risk of Predation
}

\author{
Guy Beauchamp* \\ Independent Researcher, Montréal, QC, Canada
}

Blinking serves several functions in animals, but it comes at the cost of intermittent blindness. Blinking can occur spontaneously, but it is commonly associated with head movements. As feeding animals often need to move the head down repeatedly to gather resources, intermittent blindness might represent a hitherto unappreciated cost of feeding. In addition, this cost might also be more prevalent in larger groups as feeding effort typically increases with group size. In chickens (Gallus gallus domesticus), blinks associated with head movements occurred at a high frequently during feeding bouts. While blinks tended to be short, the amount of time spent blinking was close to $50 \%$ when feeding and increased with group size. By contrast, time spent blinking was much lower when birds simply monitored their surroundings between feeding bouts. Intermittent blinking at this scale when feeding is likely to decrease the ability to detect predation threats in a timely fashion and to monitor neighbors effectively.

Keywords: blinking, chickens, group size, intermittent blindness, predation risk

\section{OPEN ACCESS}

Edited by:

Jordi Figuerola,

Estación Biológica de Doñana (CSIC),

Spain

Reviewed by:

Jose A. Masero,

Universidad de Extremadura, Spain

Sasha Raoul Xola Dall,

University of Exeter, United Kingdom

${ }^{*}$ Correspondence:

Guy Beauchamp

guygillesbeauchamp@gmail.com

Specialty section:

This article was submitted to Behavioral and Evolutionary Ecology,

a section of the journal

Frontiers in Ecology and Evolution

Received: 20 April 2017 Accepted: 10 October 2017 Published: 24 October 2017

Citation:

Beauchamp G (2017) Half-Blind to the

Risk of Predation.

Front. Ecol. Evol. 5:131.

doi: 10.3389/fevo.2017.00131

\section{INTRODUCTION}

Blinking in species with movable eyelids is essential to regenerate the liquid film that covers and protects the eye (Korb et al., 1994). In addition, blinking aids vision through a series of processes including a reduction in photoreceptor image fading (Kinsbourne and Warrington, 1963). Blinking can occur spontaneously but in birds and mammals it tends to be associated with gaze shifts caused by eye or head movements (Kirsten and Kirsten, 1983; Evinger et al., 1994; Tada et al., 2013). Blinking during such gaze shifts might serve several purposes. For instance, gaze shifts expose the eye to more debris or increase dryness, in which case blinking would serve a protective function (Nakamori et al., 1997). Rapid movements of images across the retina during gaze shifts cause blurring, and blinking might lessen the perception of visually degraded and potentially unreliable information (Wurtz, 2008).

While blinking can be beneficial, studies have revealed that at least in humans, individuals are functionally blind during and even just before the onset of a blink, which explains why blinks tend to go undetected (Volkmann et al., 1980). A high rate of blinking and/or long blink duration might thus cause intermittent blindness, and reduce the ability to visually detect threats (Johns et al., 2009). Feeding birds, in particular, often need to peck from an upright position at food items located on the substrate below. It has long been thought that feeding with the head down compromises peripheral vision and increases predation risk (Bednekoff and Lima, 2005; Tisdale and FernándezJuricic, 2009). If blinking occurs during head movements associated with feeding, birds might thus become intermittently blind during feeding bouts. This would constitute an additional and hitherto unappreciated cost of feeding.

The purpose of this study was to examine the extent to which blinking occurs during feeding bouts in chickens (Gallus gallus domesticus) and to document the amount of time individuals are functionally blind during feeding bouts and as a control when they monitor their surroundings with the head up between feeding bouts. I also examined the effect of group size on blinking during 
feeding because feeding effort tends to increase in larger groups (Beauchamp, 2015), which could lead to more intermittent blindness in larger groups.

\section{METHODS}

\section{Study Animals}

Fourteen subadult female chickens from the Bovan Brown layer breed served as experimental subjects. Chickens were individually tagged with colored rings for identification. The $3 \times$ $3 \times 3 \mathrm{~m}$ indoor pen, which housed the birds, connected through a small trap door to a similar sized covered outdoor pen. Under a 13L:11D photoperiod regime, the indoor pen included several perches for roosting and a sandy patch for dust-bathing. Wire mesh covered the outdoor pen, which allowed visual and auditory contact with the outside. Water and a commercial layer feed were available at all times. Few studies have investigated vigilance in this layer breed. When feeding alone, chickens from this breed spent nearly a third of their time vigilant (Beauchamp, 2017), a value certainly in line with estimates from wild species of birds (Beauchamp, 2010). Compared with their wild ancestors, layer breeds in general tend to show similar fear responses to predators albeit at a lower level (Schütz et al., 2001).

\section{Setup and Experimental Procedure}

I conducted trials in the outdoor pen. Each bird was first tested alone and then in randomly formed pairs on two separate days. The order of testing on a given day was selected randomly. Food was removed $1 \mathrm{~h}$ before lights out prior to a test day and trials took place the following morning $1 \mathrm{~h}$ after lights on. I transferred selected birds to the outdoor pen and allowed them $3 \mathrm{~min}$ to settle down before the trial. I uncovered a large food patch to begin a trial and allowed birds to eat for $3 \mathrm{~min}$. Each trial was videotaped from the outside of the pen.

\section{Data Collection}

Food handling of the crumbly feed always occurred in the head down position. For the analysis of blinking during feeding bouts, I restricted data collection to bouts with the head down. For the analysis of blinking between feeding bouts, I restricted data collection to bouts with the head up starting when the head stopped moving up and finishing when the head started to move down to initiate a new feeding bout. I thus ignored transitions between feeding and monitoring the surroundings.

I replayed videos frame by frame $(1$ frame $=33 \mathrm{~ms})$ and measured the duration of each blink. To measure blink duration, I counted the number of frames from the moment the eyelids started to close until the eye was fully opened again. Counting the number of frames to estimate blink duration can lead to an under- or overestimation of real blink duration. This is because a blink can start before the frame in which blinking becomes visible and end before the frame in which blinking is no longer apparent. Under- or overestimation is equally likely and so blink duration estimation should be unbiased. I estimated the error to be approximately plus or minus one-half of $33 \mathrm{~ms}$.

For blinks during feeding bouts, I gathered data on $\sim 60$ blinks per bird per trial from which I calculated blink frequency (number per min) and the percentage of the time spent blinking (the sum of all blink durations expressed as a percentage of trial duration). For average blink duration in a trial, I used the geometric mean of the duration of all recorded blinks because the distribution was right-skewed. For blinks between feeding bouts, I gathered data from the first 10 bouts during which monitoring occurred in a trial. Such monitoring bouts were much less frequent in pairs of birds (Beauchamp, 2017). I thus restricted the analysis of blinks between feeding bouts to trials with solitary birds.

\section{Statistical Analyses}

I used a linear mixed model with bird id as a random effect to examine the fixed effect of group size (1 and 2) on time spent blinking, blink frequency, and geometric mean blink duration. I obtained the intraclass correlation coefficient (\%) for each model to provide an estimate of the repeatability of the two measures for each bird. I used paired $t$-tests to compare time spent blinking, blink frequency and geometric mean blink duration when the birds were feeding or monitoring the surroundings between feeding bouts. Means and SEM are shown below.

\section{Ethics Statement}

This study was approved by the Ethics Committee of the Veterinary College of the University of Montréal, Canada.

\section{RESULTS}

When feeding, birds kept the head above the food with the bill pointing down and made repeated up and down movement of the head to grab crumbs. When feeding, nearly all blinks occurred during these up and down head movements. Between feeding bouts, birds maintained the bill close to the horizontal plane. While monitoring their surroundings, birds occasionally move their heads from side to side, and nearly all blinks occurred during such gaze shifts.

Solitary birds blinked less often when monitoring their surroundings than when feeding $(t=25.4, p<0.0001$; Figure 1). Blinks lasted longer when monitoring than during a feeding bout $(t=5.6, p<0.0001$; Figure 1). Overall, time spent blinking was nearly 5 times lower when monitoring than when feeding $(t=$ $20.1, p<0.0001$; Figure 1).

During feeding bouts, blink frequency was high when birds foraged alone [277.1 blinks per min (9.0)] or in pairs [285.3 (9.0)] but did not vary with group size $\left[F_{(1,13)}=0.49, p=\right.$ $0.50]$. Repeatability was low for blink frequency (ICC $=16 \%$ ). Geometric mean blink duration, which ranged across birds from 46 to $110 \mathrm{~ms}$, was short when birds were alone [78 ms (40)] or in pairs [82 ms (40)], but the difference was not statistically different $\left[F_{(1,13)}=0.82, p=0.38\right]$. Repeatability of average blink duration was higher (44\%). Time spent blinking ranged between 30 and $56 \%$ and was significantly higher when birds foraged in pairs $[46.1 \%(1.5)]$ than alone $\left[41.1 \%(1.5) ; F_{(1,13)}=13.2\right.$, $p=0.003$; Figure 2]. Repeatability for time spent blinking was highest (59\%). 

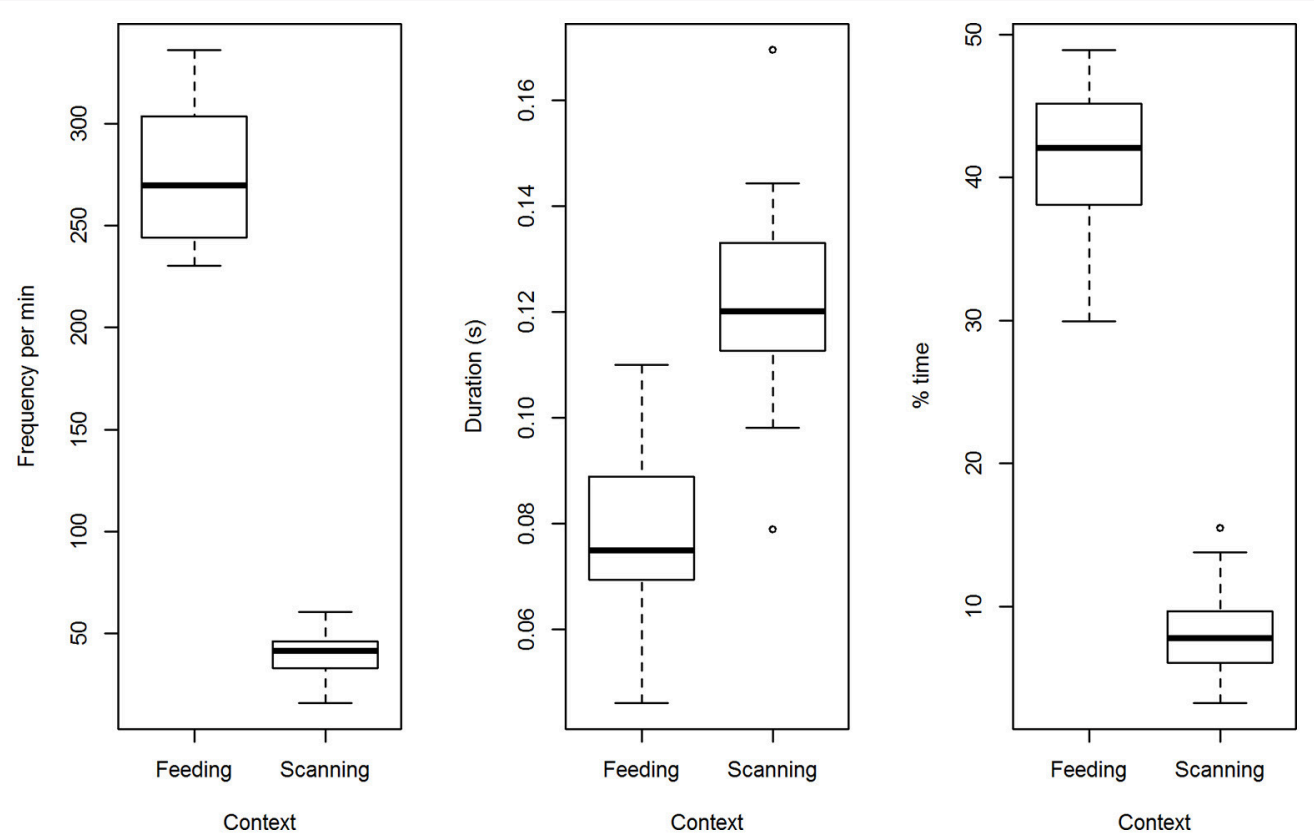

FIGURE 1 | A comparison of blinking when feeding and when monitoring the surroundings. Three different metrics of blinking are contrasted for solitary birds engaged in feeding or monitoring between feeding bouts (number of blinks per min, geometric mean blink duration and \% time spent blinking).

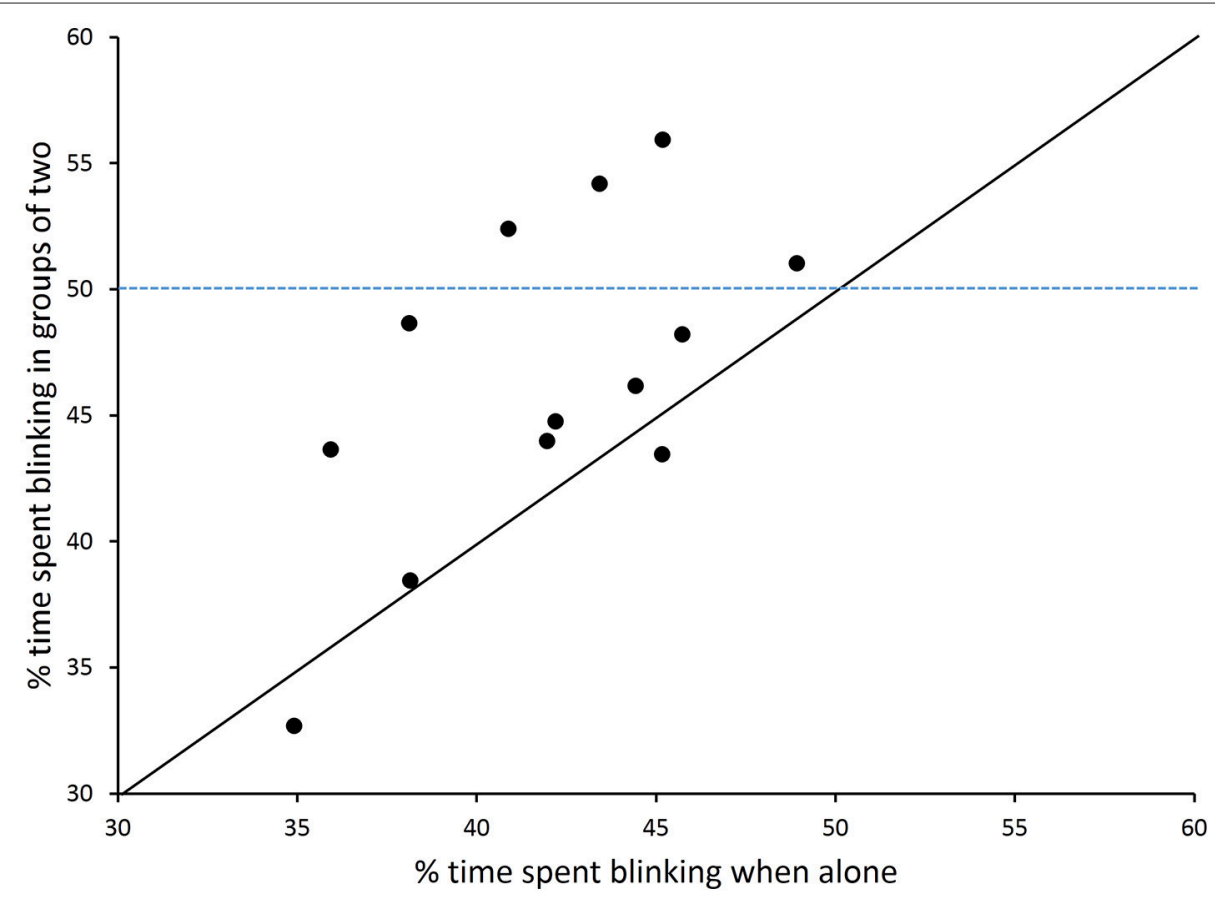

FIGURE 2 | The overall amount of time allocated to blinking (\%) during trials. The \% of time spent blinking is shown for chickens that foraged alone or in groups of two. The diagonal shows the equality line and the dashed line shows the $50 \%$ value $(n=14)$.

\section{DISCUSSION}

Chickens blinked at a high rate when feeding. Despite the fact that blinks tended to be quite short in duration, birds alone or in groups of two were functionally blind nearly half the time when feeding. Such large-scale intermittent blinking is a cost associated with feeding because time spent blinking was much lower when birds were not feeding. I also found that intermittent blinking 
increased with group size. While living in groups provides several means to reduce predation risk (Beauchamp, 2014), intermittent blinking represents a potentially novel cost of social foraging as it increases the chances of not detecting threats in a timely fashion in larger groups. This interpretation assumes that blinking leads to intermittent blindness.

Notwithstanding any potential benefits of blinking for visual perception, one implication of these results is that threat detection could be compromised nearly half the time when birds are feeding. Indeed, predator detection could be delayed by as much as $110 \mathrm{~ms}$ (or perhaps more with additional blindness preand post-blink). While this delay appears rather short, it might allow a fast-moving predator to come closer before detection. For instance, with a bird of prey moving at $25 \mathrm{~m} / \mathrm{s}$ (Hilton et al., 1999), blinking could allow the predator to move undetected for an additional $2.8 \mathrm{~m}$.

Feeding birds also monitor their neighbors for signs of alarm and can use this information to respond quickly to threats that they have failed to detect by themselves (Lima, 1995). Intermittent blinking might interfere with such collective detection, which means that foragers might need to allocate more time than expected to antipredator vigilance and rely less on neighbors to detect threats. On the other hand, blinking has been considered to act as a social cue (Curio, 2001) and could even function as a vigilance signal (Guillemain et al., 2012). Whether such social functions are relevant in chickens is not known.

The relatively high repeatability of blink duration and time spent blinking suggests that birds used different strategies to manage intermittent blinking when feeding perhaps by positioning the head at different distances from the food or by moving the head at different speeds. Such strategies might reduce the cost imposed by intermittent blinking. However, there might also be additional costs in maintaining the head lower or moving the head rapidly. Low head position during feeding, for example, can reduce the ability to detect predators (Bednekoff and Lima, 2005). A reduction in the rate of blinking might also be a means to reduce the cost of intermittent blinking in riskier settings (Cross et al., 2013; Yorzinski, 2016).

\section{REFERENCES}

Beauchamp, G. (1998). The effect of group size on mean food intake rate in birds. Biol. Rev. 73, 449-472. doi: 10.1017/S0006323198005246

Beauchamp, G. (2010). A comparative analysis of vigilance in birds. Evol. Ecol. 24, 1267-1276. doi: 10.1007/s10682-010-9358-5

Beauchamp, G. (2014). Social Predation: How Group Living Benefits Predators and Prey. New York, NY: Academic Press.

Beauchamp, G. (2015). Animal Vigilance: Monitoring Predators and Competitors. London: Academic Press.

Beauchamp, G. (2017). Difficulties in monitoring conspecifics mediate the effects of visual obstruction on the level and synchronization of vigilance. Front. Ecol. Evol. 5:12. doi: 10.3389/fevo.2017.00012

Bednekoff, P. A., and Lima, S. L. (2005). Testing for peripheral vigilance: do birds value what they see when not overtly vigilant? Anim. Behav. 69, 1165-1171. doi: 10.1016/j.anbehav.2004.07.020

Butler, S. R., Hosinski, E. C., Lucas, J. R., and Fernández-Juricic, E. (2016). Social birds copy each other's lateral scans while monitoring group mates with low-acuity vision. Anim. Behav. 121, 21-31. doi: 10.1016/j.anbehav.2016.08.002
This study uncovered a substantial cost of feeding when alone or in groups in chickens foraging in a laboratory setting. It is not clear whether domestication has influenced blinking attributes in chickens. Further studies are thus needed to determine if the findings extend to wild species and to other social foraging species. In addition, I investigated the effect of group size in small groups. As time spent feeding typically increases in larger groups (Beauchamp, 1998), it is conceivable that higher feeding rates in such groups could translate into even more time spent blinking, although this requires further empirical testing.

It is important to keep in mind that while intermittent blinking can lead to temporary blindness, blinking can be beneficial. Blinking can protect the integrity of the eye during feeding movements (Nakamori et al., 1997). It might also reduce the likelihood of responding to degraded and potentially unreliable visual information (Wurtz, 2008). As eye movements reduce afterimage duration, blinking while feeding could also eliminate earlier and currently uninformative visual information (Powell et al., 2015). Not blinking could therefore be even costlier than blinking.

Blinks associated with head movements are known in other species (Zeigler et al., 1980; Kirsten and Kirsten, 1983; Evinger et al., 1994; Tada et al., 2013; Yorzinski, 2016), and many species of birds are also known to peck at very high rates (Gillings et al., 2007; Kuwae et al., 2008). In other species, head movements can occur when looking for food (Ochs et al., 2016) or when scanning for predators (Butler et al., 2016). Intermittent blinking might thus be quite widespread in animals.

\section{AUTHOR CONTRIBUTIONS}

The author confirms being the sole contributor of this work and approved it for publication.

\section{ACKNOWLEDGMENTS}

I thank the reviewers for constructive comments.

Cross, D. J., Marzluff, J. M., Palmquist, I., Minoshima, S., Shimizu, T., and Miyaoka, R. (2013). Distinct neural circuits underlie assessment of a diversity of natural dangers by American crows. Proc. R. Soc. B Biol. Sci. 280:1046. doi: 10.1098/rspb.2013.1046

Curio, E. (2001). Wie vögel ihr auge schützen: zur arbeitsteilung von oberlid, unterlid und nickhaut. J. Ornithol. 142, 257-272. doi: 10.1007/BF01651365

Evinger, C., Manning, K. A., Pellegrini, J. J., Basso, M. A., Powers, A. S., and Sibony, P. A. (1994). Not looking while leaping: the linkage of blinking and saccadic gaze shifts. Exp. Brain Res. 100, 337-344. doi: 10.1007/BF00227203

Gillings, S., Atkinson, P. W., Bardsley, S. L., Clark, N. A., Love, S. E., Robinson, R. A., et al. (2007). Shorebird predation of horseshoe crab eggs in Delaware Bay: species contrasts and availability constraints. J. Anim. Ecol. 76, 503-514. doi: 10.1111/j.1365-2656.2007.01229.x

Guillemain, M., Fouque, C., and Figuerola, J. (2012). Consistent contrast between eyelid and iris brightness supports a role for vigilance signalling in ducks. Ibis 154, 461-467. doi: 10.1111/j.1474-919X.2012.01240.x

Hilton, G. M., Cresswell, W., and Ruxton, G. D. (1999). Intra-flock variation in the speed of response on attack by an avian predator. Behav. Ecol. 10, 391-395. doi: 10.1093/beheco/10.4.391 
Johns, M., Crowley, K., Chapman, R., Tucker, A., and Hocking, C. (2009). The effect of blinks and saccadic eye movements on visual reaction times. Atten. Percept. Psychophys. 71, 783-788. doi: 10.3758/APP.71.4.783

Kinsbourne, M., and Warrington, E. K. (1963). A study of visual preservation. Neurol. Neurosurg. Psychiatry 26, 468-475. doi: 10.1136/jnnp.26. 5.468

Kirsten, J., and Kirsten, E. B. (1983). Spontaneous blink rates of birds. Condor 85, 92-93. doi: $10.2307 / 1367896$

Korb, D. R., Baron, D. F., Herman, J. P., Finnemore, V. M., Exford, J. M., Hermosa, J. L., et al. (1994). Tear film lipid layer thickness as a function of blinking. Cornea 13, 354-359. doi: 10.1097/00003226-199407000-00012

Kuwae, T., Beninger, P. G., Decottignies, P., Mathot, K. J., Lund, D. R., and Elner, R. W. (2008). Biofilm grazing in a higher vertebrate: the Western Sandpiper, Calidris mauri. Ecology 89, 599-606. doi: 10.1890/07-1442.1

Lima, S. L. (1995). Collective detection of predatory attack by social foragers: fraught with ambiguity? Anim. Behav. 50, 1097-1108. doi: 10.1016/0003-3472(95)80109-X

Nakamori, K., Odawara, M., Nakajima, T., Mizutani, T., and Tsubota, K. (1997). Blinking is controlled primarily by ocular surface conditions. Am. J. Ophthalmol. 124, 24-30. doi: 10.1016/S0002-9394(14)71639-3

Ochs, M. F., Zamani, M., Gomes, G. M. R., de Oliveira Neto, R. C., and Kane, S. A. (2016). Sneak peek: raptors search for prey using stochastic head turns. Auk 134, 104-115. doi: 10.1642/AUK-15-230.1

Powell, G., Sumner, P., and Bompas, A. (2015). The effect of eye movements and blinks on afterimage appearance and duration. J. Vis. 15:20. doi: 10.1167/ 15.3.20

Schütz, K. E., Forkman, B., and Jensen, P. (2001). Domestication effects on foraging strategies, social behaviour and different fear responses: a comparison between the red junglefowl (Gallus gallus) and a modern layer strain. Appl. Anim. Behav. Sci. 74, 1-14. doi: 10.1016/S0168-1591(01)00156-3

Tada, H., Omori, Y., Hirokawa, K., Ohira, H., and Tomonaga, M. (2013). Eye-blink behaviors in 71 species of Primates. PLoS ONE 8:e66018. doi: 10.1371/journal.pone.0066018

Tisdale, V., and Fernández-Juricic, E. (2009). Vigilance and predator detection vary between avian species with different visual acuity and coverage. Behav. Ecol. 20 936-945. doi: 10.1093/beheco/arp080

Volkmann, F. C., Riggs, L. A., and Moore, R. K. (1980). Eyeblinks and visual suppression. Science 207, 900-902. doi: 10.1126/science.7355270

Wurtz, R. H. (2008). Neuronal mechanisms of visual stability. Vision Res. 48, 2070-2089. doi: 10.1016/j.visres.2008.03.021

Yorzinski, J. L. (2016). Eye blinking in an avian species is associated with gaze shifts. Sci. Rep. 6:32471. doi: 10.1038/srep32471

Zeigler, H. P., Levitt, P. W., and Levine, R. R. (1980). Eating in the pigeon (Columba livia): movement patterns, stereotypy, and stimulus control. J. Comp. Physiol. Psychol. 94, 783-794. doi: 10.1037/h0077818

Conflict of Interest Statement: The author declares that the research was conducted in the absence of any commercial or financial relationships that could be construed as a potential conflict of interest.

Copyright (c) 2017 Beauchamp. This is an open-access article distributed under the terms of the Creative Commons Attribution License (CC BY). The use, distribution or reproduction in other forums is permitted, provided the original author(s) or licensor are credited and that the original publication in this journal is cited, in accordance with accepted academic practice. No use, distribution or reproduction is permitted which does not comply with these terms. 